\title{
A Comparative Study of Two Schools: How School Cultures Interplay the Development of Teacher Leadership in Mainland China
}

\author{
Feiye Wang, Sally J. Zepeda \\ Department of Lifelong Education, Administrating, and Policy, University of Georgia, Athens, USA \\ Email:wfy275@uga.edu \\ Received July 2013
}

\begin{abstract}
This article seeks to gain an understanding of the interrelated relationship between school cultures and the teacher leadership development by comparing the experience of teacher leaders' from two middle schools in China that exhibited different kinds of school culture. The researchers argue that the better the school culture was, the more prospective Teacher leaders would develop and the better Teacher leaders would enact their leadership, which further would reinforce the building of a healthy school culture.
\end{abstract}

Keywords: School Culture; Teacher Leadership; Teacher Leader; Mainland China

\section{Introduction}

Over the past decades, research has consistently underscored leadership as a critical key to school improvement (Hart, 1995; Wong \& Nicotera, 2007). However, scholars (e.g., Lambert, 2002; York-Barr \& Duke, 2004) indicated that the principal as the sole leader is no longer an effective model. And the central role teacher leadership plays in school improvement efforts has been gradually identified as a way to extend the leadership of the principal (Harris \& Muijs, 2003; Murphy, 2005). Although there is a commonly held belief in the United States that teacher leadership can have a wide range of impact, it has not been easy to promote the development of teacher leadership because it has been reported that assuming teacher leadership roles and responsibilities alters some traditional norms and beliefs that teachers hold within the cultures in which they work (Murphy, 2005).

This article seeks to gain an understanding of the interrelated relationship between school cultures and the teacher leadership development by comparing the experience of teacher leaders' from two middle schools in China that exhibited different kinds of school cultures. Both schools are located in the same district with similar school policies and regulations and engaged in a series of activities to implement new educational reform. The researchers argue that the better the school culture was, the more prospective Teacher leaders would develop and the better Teacher leaders would enact their leadership, which further would reinforce the building of a healthy school culture. The findings related to the performance of teacher leaders and school improvement from these two schools provided solid evidence for the interplay between school cultures and teacher leadership development.

The remainder of the paper is comprised of five sections. In the first section, the research literature and the relationship among teacher leadership, school culture, and school improvement are reviewed. The second section describes the research methods employed in the study. The third section summarized the background of this study with regard to relevant policy con- text and school data. The fourth section presents findings regarding the culture difference and the interplay between school culture and teacher leadership. Finally, the conclusions and implications of the findings are discussed.

\section{Teacher Leadership, School Culture, and School Improvement}

Katzenmeyer and Moller (2009) defined the concept of teacher leadership, stating, "Our definition is teacher leaders lead within and beyond the classroom; identify with and contribute to a community of teacher learners and leaders; influence others toward improved educational practice; and accept responsibility for achieving the outcomes of their leadership (p. 6). Literature reported that teacher leaders have a solid foundation of teaching experience and expertise and are respected by their peers (York-Barr \& Duke, 2004). Most commonly, teacher leaders are assuming formal positions (e.g., department chairs, curriculum leaders, etc.), or with formal titles (e.g., mentor, master teacher, National Board Certified Teachers, etc.) to influence and help other teachers to perform better, to participate in decision making, to contribute to the development of learning communities, or to provide key professional development (Darling-Hammond, Bullmaster, \& Cobb, 1995; Moller \& Katzenmeyer, 1996; Murphy, 2005; Zepeda, 2011).

School culture is broadly accepted as a dominant ingredient in overall school success (Fullan, 2001; Valentine, 2006; YorkBarr \& Duke, 2004). According to Barth (2002), school culture is a complex pattern of norms, attitudes, beliefs, behaviors, values, ceremonies, traditions, and myths that are deeply ingrained in the very core of the organization. Culture is the historically transmitted pattern of meaning that wields astonishing power in shaping what people think and how they act (p. 7).

Teacher leadership and a positive and collaborative school culture promote and influence each other forming a virtuous circle of the constant improvement of the school.

Teacher leadership is considered as "a vehicle for teacher 
professional development and improvement in school organization and classroom instruction” (Smylie, 2008: p. ix). Teacher leadership promotes mutual learning between teachers and fosters a more collaborative way of working toward collective goals (Harris, 2003), which provide solid foundations for building a positive and collaborative school culture. The literature indicated that a healthy school culture is usually marked by professional collaboration and professional learning among all members of the organization with a common core of values and beliefs (e.g., Leonard, 2002; Valentine, 2006; Zepeda, 2013). Therefore, through collaboration and collegiality, with the goal of promoting the professionalization of all teachers, teacher leadership strengthens the building of a healthy school culture and further enhances the capacity for change and improvement at both the school and classroom levels (Harris \& Muijis, 2003).

School culture is regarded as a condition influencing teacher leadership (York-Barr \& Duke, 2004). Teachers’ professional relationships were characterized by privacy, autonomy, and equality in the United States (Murphy, 2005). The norm of individual autonomy has bred a culture of isolation, which inhibits teachers from interacting with their teaching colleagues and administrators and exerting influence outside their classrooms (Wasley, 1991). The norm of professional privacy was defined as "freedom from scrutiny and the right of each teacher to make independent judgments about classroom practice” (Little, 1988: p. 94), which is closely related to cultures of non-interference and non-judgmentalism. The norm of equality suggests that all teachers hold equal positions and ranks except for seniority (Wasley, 1991). Teacher leadership requires a collaborative culture and frequent interaction with teaching colleagues and brings about differentiated status based on knowledge, skills, and initiative, which breaches all three norms of autonomy, privacy, and equality, assaults the culture of isolation, non-interference, and equality in most American schools (Murphy, 2005). Therefore, "a prerequisite for successful and effective teacher leadership is changing the culture of schools" so that old norms are replaced with new norms of collaboration and teamwork (Teacher Leadership Exploratory Consortium, 2008: p. 12).

This study took place in two public middle schools in China. The norms of autonomy, privacy, and equality for American schools are replaced by collectivism, elitism, and hierarchism for Chinese schools. The value placed on elite and hierarchical management has enabled the legitimacy of ranks with different tiers of titles based on professional expertise in every field including education. Compared to American schools, the belief in collectivism has formed a more relatively collaborative culture in Mainland China's schools in which group lesson studies, group class observations, and group evaluations are the customary responsibilities of teachers (Ding, 2004). Chinese teachers are usually organized into teacher research groups, which are led by a teacher leader who is identified as one of the best in that group. Teachers in the same group share office space and have common meeting times to discuss and exchange teaching experience and skills (Preus, 2007). As a matter of fact, from the perspectives of established norms in schools, the development of teacher leaders in Mainland China seems to be evolving more naturally than in the United States.

Therefore, in this study, the Chinese teacher leaders would not face the challenging norms which their American colleagues typically face. Without considering the influencing of these three norms, this study might more clearly present the relationship between school cultures and the prospects for teacher lea- dership by comparing how different school cultures enable teacher leaders to do their work in two Chinese middle schools.

\section{Methods}

A qualitative methodology was adopted in this study to support "an inquiry process of understanding a social or human problem, based on building a complex, holistic picture, formed with words, reporting detailed views of informants, and conducted in a natural setting” (Creswell, 1994: pp. 1-2). To understand the relationship between teacher leadership development and school culture building at two research sites in Mainland China, the use of qualitative methodology was imperative.

\section{Data Selection}

The purpose of the study was to explore the interplay between the teacher leadership development and the school culture building. How teacher leaders enacted their leading roles within the cultures that might support or challenge the development of their leadership in public middle schools in Mainland China was examined and compared. It was important to select participants diversely from the groups of teacher leaders, their peers, and principals in the schools with different school environments because the researchers sought to understand further the interaction among these school members. The research site and participants were both purposefully selected because purposeful sampling "leads to selecting information-rich cases for study in depth" (Patton, 2002: p. 46, italics in the original).

The research sites were two public middle schools both located in the QP District in HA City in Mainland China. All of the names in the study that refer to the schools, cities, district, and participants were pseudonyms. In this study, deviant case sampling was used (Patton, 2002) to identify the two public schools as examples of a high-performing school and a lowperforming school. The selection of a high-performing school and a low-performing school was in accordance with the local educational administrative rating system, which was based on the 2011-2012 Unified Public School Entrance Examination scores. In addition, both of the schools had implemented the new curriculum reform, which required teacher leaders to take the lead in developing the school-based curriculum.

Therefore, the top middle school in the QP District, KM Middle School, as a high-performing school, which met all the criteria for site selection, was chosen as one research site for this study. SY Middle School, as a low-performing school in the QP District, was chosen as another research site because the school rules and policies in SY Middle School were very similar to those in KM Middle School. With the purpose of improving all schools, in 1992, the Department of Education in HA City enacted a policy to form a partnership between a high-performing school and a low-performing school to assist the lowperforming school in making progress with the help of a highperforming school. Fortunately, SY Middle School was assigned KM Middle School as its partner from 1992 to 1998. Therefore, SY Middle School apparently learned a lot from KM Middle School. The rules and regulations related to professional development and instruction such as lesson plan study meetings, department teaching and research activities, monthly examinations, and school teaching competitions were very similar in both KM Middle School and SY Middle School.

Two teacher leaders and two of their teaching colleagues, as 
well as one principal from each school were purposefully chosen as participants in this study. In total, there were 10 participants, including 8 teachers and 2 principals respectively from KM Middle School and SY Middle School in the QP District in HA City. There were three groups of participants - teacher leaders, teaching peers, and principals-from KM Middle School and SY Middle School. Selected teacher participants met the following criteria: (1) teacher leader participants taught Chinese, Mathematics, and English in these schools, and their counterpart participants, teaching peers, were selected for teaching identical subjects; (2) teacher leader participants and their peer participants shared the same office; and (3) teacher leader participants were recommended to the researcher by the principals at the two school sites, KM Middle School and SY Middle School.

Chinese, Mathematics, and English are core courses for Chinese middle school teachers, which are also the main subjects included in the high school entrance examination. Teachers teaching core courses were usually engaged in more curricular and instructional activities in the school compared to teachers teaching other subjects. The recommended teacher leaders assumed school leader positions such as the Department Chair, the Subject Chairperson of one specific grade, and the school supervisor. Furthermore, the recommended teacher leaders all earned many honorable titles related to curriculum and instruction such as the Academic Leader, the Teaching Master, and the Teaching Expert. Unlike in the United States, in Mainland China, students usually do not change classrooms, but instead, the teachers are mobile and able to go to different classrooms to teach. Thus, teachers in Mainland China, like administrators, always have independent offices separate from the classrooms. To capture more interaction among the teacher leaders and their teaching peers, the teachers teaching the same subjects and sharing the same office with the recommended teacher leaders were selected.

\section{Data Collection and Analysis}

The use of multiple data-collection methods can "contribute to research trustworthiness and verisimilitude, or sense of authenticity" (Glesne, 2011: p. 48). In this study, after giving the participants the consent forms and demographic sheets to fill in, the data were collected through interviews, observations, shadowing experiences, and artifacts and documents, in accordance with the study's pursuit of participants' perspectives of the influence of school culture and teacher leadership development.

Interviewing allows researchers the ability to enter into participants' perspectives to gather their stories and construct meanings (Patton, 2002). To gain personal accounts from participants in a limited time, the semi-structured interviews were used. The interview question guided the conversations with the individual groups of participants, and the semi-structured interview for each participant lasted approximately two hours. Follow-up interviews with participants were not planned to occur unless stray categories emerged from the data and required further information or elaboration from specific participants. All participants agreed to possible follow-up interviews, but no follow-up interview actually occurred. With participants' permission, all the interview conversations were recorded. In the meantime, field notes were written during the interviews.

To capture how the Backbone Teachers exerted their leader- ship in the Chinese middle school context, observations were conducted by the researchers at the research sites. Observations were performed during the regularly scheduled formal meetings hosted by the principal and regular activities including weekly lesson study meetings and weekly teaching and research activities led by teacher leaders in the two schools.

Shadowing is "a research technique which involves a researcher closely following a member of an organization over an extended period of time” (McDonald, 2005: p. 456) to capture behaviors and perspectives. In this study, the researchers shadowed in total four teacher leaders each for one week outside of their classroom environments in the two schools. When shadowing the teacher leaders, the researchers often asked questions on site, and the participants answered those questions quickly and even provided more illustrations to amplify their responses. Field notes of observations and shadowing experiences were taken to record the events, and the filed notes were further expanded soon after each encounter.

Artifacts and documents about the literature on teacher leadership in both United States and China, the research context included basic school information and participant information, and methodological notes were searched and reviewed. Furthermore, memos were written to record insights gained from data collection and data coding, which were considered as data, too.

The constant comparative method was adopted to conduct the data analysis for this study. This study strictly followed the four stages of constant comparative analysis-(a) comparing incidents, (b) integrating categories and their properties, (c) delimiting the theory, and (d) writing the theory-so as to "generate theory more systematically" (Glaser, 1994: p. 182). With the research purpose as the guiding framework, data coding was conducted to develop categories, patterns, and themes. Eventually, several major themes for this study were constructed based on the framework.

\section{Context}

In 2002, a new round of curriculum reforms, with the same theme of promoting quality-oriented education, formally began in Mainland China. The new curriculum reform emphasized the diversity and usefulness of the curriculum, especially schoolbased curriculum or activities, called for an increase in formal or informal training programs for teachers to serve new students learning demands for a quality-oriented education (Minister of Education in China, 2001). The teacher leaders are expected to play the key role in initiating new school-based curriculum and activities and promoting teacher professional development in this new wave of educational reform in China. Since 2002, all the public schools in the QP District have begun to implement the new curriculum reform.

This study took place in KM Middle School, representing a high-performing school, and SY Middle School, representing a low-performing school. These two middle schools were both located in an urban area of the QP District in Mainland China. In 2012, KM Middle School supported approximately 3,100 students in 52 classes from grade 7 to grade 9 with 200 faculty members, while SY Middle School supported 890 students in 22 classes from grade 7 to grade 9 with 102 faculty members. The percentage of teachers with bachelor's degrees or higher degrees in KM Middle School was $100 \%$, in which more than $10 \%$ of the teachers had master's degrees, while the average 
percentage of middle school teachers with bachelor's degrees or higher degrees in SY Middle School was $49 \%$ and $62 \%$ for the QP District.

KM Middle School had an abundant number of teacher leaders with various titles and honors. For instance, until 2012, there were 9 teachers receiving national-level honors and 14 teachers receiving provincial-level honors, not to mention a large number of teachers who received city-level honors and district-level honors. However, so far, the highest level of honor for the teacher leaders at SY Middle School was at the district-level. Teachers in KM Middle School were extremely good at cultivating higher levels of student achievement, and for many years, the school had won awards for being an excellent teaching community.

The students' achievement for SY Middle School was just passable compared to other schools in the QP District and much lower compared to KM Middle School. The average scores in 2011 on the Unified High School Entrance Examination for SY Middle School were 530.57, while the scores averaged 697.36 for KM Middle School, 519.17 for the QP District school system, and 513.21 for the whole HA Public Middle School System. Based on the variable of average scores, SY Middle School ranked 4th out of the 9 schools in the QP District and 33rd out of 155 schools in HA City. Table 1 Table 4.3 shows the detailed data comparison between KM Middle School and SY Middle School.

\section{Findings}

Three major themes were constructed in this study. The first theme is the discussion of the different culture in the two schools. The second theme is related to the influence of school culture on teacher leadership development. The third theme is referring to the teacher leaders' impact on building a healthy school culture.

\section{Comparison of Culture Indicators}

There existed a partnership between KM Middle School and SY Middle School from 1992 to 1998. To help SY Middle School improve, during that period, KM Middle School constantly sent experienced teachers to SY Middle School to coach teachers, to share lesson plan models, to examine papers and subject assignments, and to conduct professional development projects together. Therefore, until now, the rules and regulations related to professional development and instructions such as mentor programs, lesson plan study meetings, department teaching and research activities, monthly examinations, and school teaching competitions were still very similar in both KM Middle School and SY Middle School. However, all the participants including the teacher leaders, their teaching peers, and the principal from KM Middle School proudly indicated that they had a healthy school culture, while all the participants from SY Middle School admitted with a little embarrassment that their school culture was not as healthy as KM Middle School, which was also strongly felt by the researcher.

The interview and observation data showed three dominant indicators that clearly distinguished the cultures of these two schools: 1) positive attitude toward learning, 2) collaboration, and 3) relational trust. Teachers in KM Middle School vigorously pursued learning. They grasped every learning opportunity to improve their knowledge and skills. Teachers from KM
Table 1.

Data Comparison between KM middle school and SY middle school during the 2011-2012 school year.

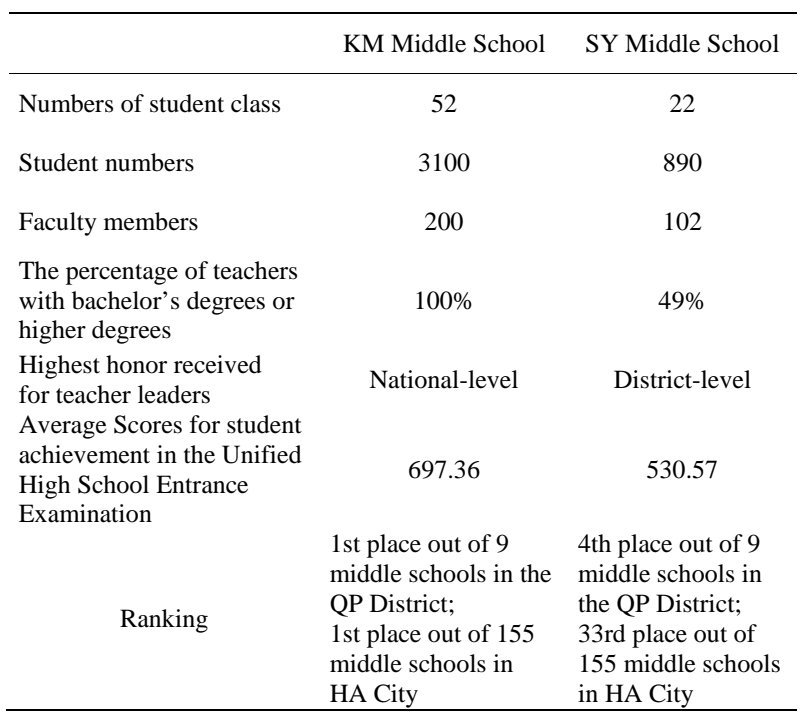

Middle School participated in the regular lesson study meetings and activities with positive attitudes and made their own contributions by asking questions, sharing ideas, and providing feedback. Compared to KM Middle School, the similar activities in SY Middle School were more casual, with rare discussions or feedback. Many teachers at SY Middle School apparently just "lazed away" without much desire to learn.

Although both KM Middle School and SY Middle School had regular professional development programs that needed collaboration such as lesson plan study, mentor programs, the range of collaboration at KM Middle School was much wider than that at SY Middle School. The participants from SY Middle School frankly admitted that they actually worked alone except for the required collective activities. In contrast, teachers at KM Middle School were more actively participated in differrent kinds of collaborative activities. The observation data of individual teacher's preparation for teaching competitions clearly demonstrated the different degree of collaboration. At SY Middle School, the individual teacher prepared the teaching competition alone. However, at KM Middle School, all group members which the teacher belonged to collaborated together to help the teacher prepare for the teaching competitions by sharing ideas and providing advice. Except for the required collective activities, other collaborative activities (e.g., voluntary class demonstrations with observations) were often observed at $\mathrm{KM}$ Middle Schools, but rarely at SY Middle School.

The teacher leaders at KM Middle School earned the trust from their peers and from the principal. The repeated interactions signaled that teachers accepted the teacher leaders' professional judgment without hesitation clearly showing the trust from the teacher leaders' peers at KM Middle School. The principal empowered teacher leaders at KM Middle School to initiate and lead different kinds of curricular and instructional activities, and he gave the recommendation authority to the teacher leader. He indicated that he trusted the expertise of his teacher leaders and was satisfied with their performance.

However, it was a different case at SY Middle School. The principal at SY Middle School was not satisfied with the cur- 
rent teacher leaders' performance. He thought teacher leaders at SY Middle School could neither follow the trends in the educational field nor figure out creative activities to impress the students and teachers within the schools. Therefore, almost every new plan, activity, or project at SY Middle School was initiated by the principal because he could not trust the teacher leaders' "creativity" and "an overall view" of teaching and learning in his building. The teacher leaders at SY Middle School were not sure about their leading role. Their uncertainty about their leading impact on their peers apparently reflected that the relationships between the teacher leaders and their peers were not of trust and respect.

In brief, KM Middle School had a healthier school culture than SY Middle School. Teachers and the principal had formed a learning community with collaboration and trust at KM Middle School, while teachers and the principal still needed to nurture a positive school culture through strengthening mutual learning, promoting wider collaboration, and building more trust among teachers and between teachers and the principal.

\section{The Influence of School Culture on Teacher Leadership Development}

The comparison data from KM Middle School and SY Middle School showed that school culture plays a significant role in developing teacher leadership. With a healthy culture, more prospective teacher leader could develop. The teacher leaders from KM Middle School clearly expressed that a positive and collaborative culture had become a major reason why they would stay at KM Middle School. They admitted that the positive culture consistently reminded them to become better and they were cultivating more potential teacher leaders in their groups within such a collaborative culture by sharing what they learnt. The teacher leaders' peers from KM Middle School commented that within a positive and collaborative culture, more teachers would have enough qualifications for becoming teacher leaders. The principal from KM Middle School agreed that within a positive and collaborative school culture, teachers were willing to learn new knowledge, to exchange ideas, and to share experiences with each other, which could lead to the improvement of their professional knowledge and skills and the emergence of teacher leaders.

At SY Middle School, although the teacher leaders did not consider the culture as a necessary condition for the development of teacher leadership, their peers and principals both emphasized the influence of the school culture on developing teacher leaders. One teacher participant claimed that a bad culture would "awake the lazy nature," and he would "drift along" like other teachers in the school. Another teacher indicated that such a culture would "marginalize the teacher with learning pursuits from the whole teacher group" and "worsen the positive impact brought about by Backbone Teachers.” And the principal claimed that lack of a positive school culture made it hard to develop Backbone Teachers among those teachers without learning pursuits.

With a healthy school culture, teacher leaders can enact their leading roles efficiently and further had a positive impact. At KM Middle School, the teacher leaders were confident with their leading role and positive impact on their peers. They expressed that with a positive and collaborative culture, the new knowledge and good instruction can be spread and learnt quickly among their peers. Their peers and the principal confirmed the teacher leaders' claim and satisfied with teacher leaders' performance in the school. The high achievement of students with almost no difference between in teacher leaders' classroom and in their peers' classroom clearly provided some evidence for the effective impact of teacher leaders on their peers through sharing good instructions.

Within a healthy culture, the principal trusted his teacher leaders and were willing to give power to his teacher leaders. The principal of KM Middle School empowered the teacher leaders to lead in curricular and instructional field and provided every support the teacher leader needed at KM Middle School. Consequently, many projects and works initiated and led by the teacher leaders at KM Middle School become successful models for other school teachers to learn. Briefly, the teacher leadership flourished at KM Middle School within such a healthy culture characterized by trust among school members.

However, at SY Middle School, the teacher leaders doubted their leading impact since they were not sure whether their peers learned from them. Considering the culture in SY Middle School was not positive and collaborative, the teacher leaders in SY Middle School believed that they only had great impact on teachers who wanted to learn, but their efforts seemed to be wasted on teachers who did not wish to learn or advance. In addition, the principal from SY Middle School were not satisfied with the performance of teacher leaders and the current school culture. The principal at SY Middle School complained that his teacher leader lack of "creativity" and "an overall view" of teaching and learning in his building. Therefore, he did not trust them to do their leading job and was not willing to empower them. As a consequence, with such a culture of distrust, the teacher leader at SY Middle School just organized and implemented the activities initiated by the principal. Therefore, the teacher leader at SY Middle School considered them as "executants" rather than "leaders".

\section{The Teacher Leaders' Impact on Building a Healthy School Culture}

Data from KM Middle School provided evidence that the development of teacher leadership also reinforce the building of the healthy school culture. The teaching peer participants at KM Middle School showed enough respect and trust for the teacher leaders and they expressed that the teacher leaders were their role models and they were highly influenced by the teacher leaders' attitudes and behaviors. As the teacher leaders at KM Middle School recalled that before they became teacher leaders, they leaned a great deal from the former teacher leaders who were actively sharing experience, exchanging ideas, and offering solutions with them. Now they were doing the same things with their peers that the former teacher leaders had done with them. The support and empowerment from the principal and the respect from their peers enabled the teacher leaders to enact their leadership efficiently. Therefore, a virtuous circle had been formed that the more teacher leaders developed, the more similar collaborative interactions would occur and reinforce a more healthy school culture.

The same situation had not occurred at SY Middle School where teacher leadership did not flourish. Without the empowerment of the principal, teacher leaders considered themselves as executants of the principal instead of the leader among teacher groups. Compared to teacher leaders at KM Middle School, the teacher leaders' leading impact was very weak at SY Mid- 
dle School. In addition, unlike KM Middle School, the teacher leaders at SY Middle School had no established custom of actively participating in the interactions with peers. The experience of becoming teacher leaders only reflected their own active learning pursuit but did not show the active help or guidance from the former teacher leaders. As a consequence, teacher leaders actively retained and enhanced a healthy culture at KM Middle School, while the developed teacher leaders at SY Middle School seemed to not have an impact on building a healthy school culture.

\section{Conclusions and Implications}

In summary, the teacher leadership and the school culture were two interrelated factors. A healthy culture marked with positive learning attitudes, a wide range of collaboration, and trust provides a foundation for teacher leadership. At KM Middle School with a healthy school culture, more prospective teacher leaders developed and the current teacher leaders were able to exert their leadership efficiently with a positive impact. At SY Middle School with a unhealthy school culture, it was hard to develop teacher leaders and the current teacher leaders were not able to do their leading job and might not have efficient impact on their peers.

The development of teacher leadership could reinforce the building of a healthy school culture with conditions that teacher leaders should actively and efficiently play their leading roles. KM Middle School flourished with teacher leaders actively participating in different kinds of interactions with their teacher peers, and this retained a very healthy culture. At SY Middle School, although teacher leaders developed, their passive participation in interactions among their teacher groups and lack of trust from the principal and the peers enabled them not to be able to exert their leadership efficiently and actively. Hence, they did not have a strong impact on building a healthy school culture.

The current literature on culture and teacher leadership mostly focused on the confrontation of American schools' norms as an inevitable part of school culture (e.g., Little, 1988; Murphy, 2005; Wasley, 1991). This study might provide fresh insight on the interrelationship between teacher leadership and school culture without considering the existing norms of American schools. Through comparing data from different schools, evidence emerged showing the interrelated link between teacher leadership development and school culture building. More researches are needed to examine such an interrelationship from a variety of perspectives or through different methodologies so as to confirm or disconfirm the findings of this study. Moreover, school leaders and educational scholars might need to consider how to use the interrelated link between teacher leader and school culture to achieve school improvement.

\section{REFERENCES}

Barth, R. (2002). The culture builder. Educational Leadership, 59, 611.

Creswell, J. W. (1994). Research design: Qualitative and quantitative approaches. Thousand Oaks, CA: Sage.

Darling-Hammond, L., Bullmaster, M. L., \& Cobb, V. L. (1995). Rethinking teacher leadership through professional development schools. The Elementary School Journal, 96, 87-106.

http://dx.doi.org/10.1086/461816

Ding, G. (2004). Teachers' professional leadership: The team plan. Re- search in Educational Development, 10, 20-33.

Fullan, M. (2001). Leading in a culture of change. San Francisco, CA: Jossey-Bass.

Glaser, B. G. (1994). The constant comparative method of qualitative analysis. In B. G. Glaser (Ed.), More grounded theory methodology: A reader (pp. 182-196). Mill Valley, CA: Sociology Press.

Glesne, C. (2011) Becoming qualitative researchers: An introduction (4th ed.). Boston, MA: Pearson.

Harris, A. (2003). Teacher leadership as distributed leadership: Heresy, fantasy or possibility? School Leadership \& Management, 23, 313324. http://dx.doi.org/10.1080/1363243032000112801

Harris, A., \& Muijs, D. (2003). Teacher leadership and school improvement. Education Review, 16, 39-42.

Hart, A. W. (1995). Reconceiving school leadership: Emergent view. The Elementary School Journal, 96, 9-28. http://dx.doi.org/10.1086/461812

Katzenmeyer, M., \& Moller, G. (1996). Awakening the sleeping giant: Leadership development for teachers. Thousand Oaks, CA: Corwin Press.

Katzenmeyer, M., \& Moller, G. (2009). Awakening the sleeping giant: Helping teachers develop as leaders. Thousand Oaks, CA: Corwin Press.

Lambert, L. (2002). A framework for shared leadership. Educational Leadership, 59, 37-40.

Leonard, L. (2002). Schools as professional communities: Addressing the collaborative challenge.

http://mdestream.mde.k12.ms.us/sped/ToolKit/Articles/Administrati on-Systems\%20Change/Leonard\%20Ldrshp\%20Lrning\%202002\%2 0collab\%20culture\%20and\%20change.htm

Little, J. W. (1988). Assessing the prospects for teacher leadership. In A. Lieberman (Ed.), Building a professional culture in schools (pp. 78-106). New York, NY: Teachers College Press.

McDonald, S. (2005). Studying actions in context: A qualitative shadowing method for organizational research. Qualitative Research, 5, 455-473. http://dx.doi.org/10.1177/1468794105056923

Minister of Education in China (2001). The guideline of basic education curriculum reform (the pilot version).

http://www.moe.gov.cn/publicfiles/business/htmlfiles/moe/moe_309/ 200412/4672.html

Murphy, J. (2005). Connecting teacher leadership and school improvement. Thousand Oaks, CA: Sage.

Patton, M. Q. (2002). Qualitative research \& evaluation methods (3rd ed.). Thousand Oaks, CA: Sage.

Preus, B. (2007). Educational trends in China and the United States: Proverbial pendulum or potential for balance? Phi Delta Kappan, 89, 115-118.

Smylie, M. A. (2008). Forward. In M. M. Mangin, \& S. R. Stoelinga (Eds.), Effective teacher leadership: Using research to inform and reform (pp. ix-x). New York, NY: Teachers College Press.

Teacher Leadership Exploratory Consortium (2011). Teacher leader model standards. http://teacherleaderstandards.org/downloads/TLS_Brochure.pdf

Valentine, J. (2006). A collaborative culture for school improvement: Significance, definition, and measurement. http://education.missouri.edu/orgs/mllc/Upload\%20Area-Docs/MLL C\%20Culture\%20Research\%20Summary.pdf

Wasley, P. A. (1991). Teachers who lead: The rhetoric of reform and realities of practice. New York, NY: Teachers College Press.

Wong, K., \& Nicotera, A. (2007). Successful schools and educational accountability: Concepts and skills to meet leadership challenges. Boston, MA: Pearson Education

York-Barr, J., \& Duke, K. (2004). What do we know about teacher leadership? Findings from two decades of scholarship. Review of Educational Research, 74, 255-316. http://dx.doi.org/10.3102/00346543074003255

Zepeda, S. J. (2011). Professional development: What works (2nd ed.). Larchmont, NY: Eye on Education.

Zepeda, S. J. (2013). The principal as instructional leader: A practical handbook (3rd ed.). Larchmont, NY: Eye On Education. 